\title{
Nitroaromatic bis(2-hydroxyethyl)dithioacetals and oxathioacetals using 2-mercaptoethanol in the presence of chlorosilanes
}

\author{
Lyubov K. Papernaya,* Alexandra A. Shatrova, Alexander I. Albanov, Lyudmila V. \\ Klyba, \\ and Galina G. Levkovskaya
}

A. E. Favorsky Irkutsk Institute of Chemistry, Siberian Branch, Russian Academy of Sciences, 1 Favorsky Str., 1, Irkutsk 664033, Russia

E-mail:papern@irioch.irk.ru

\begin{abstract}
Thioacetalization of the nitrobenzaldehydes with 2-mercaptoethanol is easily carried out in the presence of $\mathrm{TMSCl}$ and dichlorodimethylsilane without heating and using of additional solvent. The reaction direction is defined by the reagents ratio and led to formation of bis(2hydroxyethyl)dithioacetals (yield 76-91\%) or 1,3-oxathiolanes (yield 76-91\%).

Bis(2-hydroxyethyl)dithioacetals are easily transformed in the corresponding 1,3oxathiolanes at long storage without heating or influence of catalysts, and also under electronic and chemical ionization.
\end{abstract}

Keywords: Aldehydes, catalysis, thioacetals, chlorosilanes, bis(2-hydroxyethyl)dithioacetals

\section{Introduction}

Nitro-substituted aromatic and heterocyclic compounds possess important biological activities $^{1}$ and are potential sources of the nitric oxide in living organisms. ${ }^{2}$ Nitro-substituted arenes and hetarenes are used frequently for synthesis of the densely functionalized arenes and heterocyclic compounds. ${ }^{3}$ Hence, studies of the nitrobenzaldehydes synthesis potential, in particular, creation of the carbonyl group protection methods as oxathioacetals and thioacetals present an urgent problem. One of the most convenient and promising methods for the carbonyl group protection to prepare novel and applicable polyfunctionalized nitroarenes and nitrophenylsubstituted heterocyclic compounds is an acetalization and thioacetalization of the nitrobenzaldehydes. ${ }^{3 \mathrm{~b}, \mathrm{~g}}$

In turn, the acetals are the precursors for the synthesis of compounds related to the benzofurans and indoles series, which are applied widely in the medicine. ${ }^{4}$ The fivemembered oxathiolane ring occurs in nucleoside congeners that possess a pronounced antiviral activity. ${ }^{5}$ 2-Aryl-1,3-oxathiolanes are efficiently converted into 2-aryl-1,4oxathiane $^{6}$, acetals ${ }^{7}$, monosulfoxides. ${ }^{8}$ Cyclic dithio- and oxathioacetals are employed in the 
reactions involving the ring-expansion ${ }^{9}$ or ring-opening ${ }^{10}$ of the thioacetal core, as well as an acyl anion equivalent in the carbon-carbon bond-forming reactions. ${ }^{11}$ Open-chain thioacetals are used in the reactions of the carbon chain expansion. ${ }^{12}$ Synthetic applications of the thioacetal function were extensively described in the review. ${ }^{13}$ Thus, urgency of the development of novel and efficient methods for the preparation of oxathio- and dithioacetals is due to the growth of their synthetic and practical usage. It is known that synthesis of the oxa- and thioacetals from carbonyl compounds proceeds via the catalysis with proton acids, ${ }^{14,15}$ Lewis acids, ${ }^{16-20}$ ets. ${ }^{21,22}$ Some of these methods possess a low chemoselectivity, require hard reaction conditions, utilization of expensive or toxic catalysts and reagents, inert gas environment, long reaction time or an additional and complicated processing of the reaction mixture when the final products are separated.

In a few earlier papers we reported chemoselective reaction of acetalization of the tiophene series carbaldehydes with the alkanthiols, -dithiols and -diselenol under moderate ($8 \div 0{ }^{\circ} \mathrm{C}$ ) temperatures to furnish the open-chain and cyclic thio - and selenoacetals, which were not described earlier. ${ }^{23-26}$ This reaction was performed using the chlorotrimethylsilane (TMSCl) as an medium and a catalyst. The benefits of TMSCl application in the aldehydes acetalization are that hydrogen chloride is generated in situ through the thiols (dithiols, diselenols) interaction with TMSCl. The latter further gives a proton when the chlorine anion bounds with the silyl cation. In the process, the carbonyl group is protonated that is necessary for acetalization, and this allows the aggressive environment to be avoided. The application of $\mathrm{TMSCl}$, which is not a superacid, is rather attractive for the effective acetalization of the aldehydes with unstable in acid substitutes. Another valuable feature of $\mathrm{Me}_{3} \mathrm{SiCl}$ is that it enables any water absorbents to be excluded from the reaction. Indeed, water, evolved during the synthesis, is scavenged by $\mathrm{Me}_{3} \mathrm{SiCl}$, to produce hexamethyldisiloxane (HMDS) and hydrogen chloride. Hydrogen halide formed upon hydrolysis of TMSCl further increases the catalytic activity of the system. In addition, after the reaction is completed, both HMDS and TMSCl excess are separated readily from the reaction products. It has been reported that $\mathrm{TMSCl}$ is an efficient water scavenger that permits it to be applied not only for the acetalization but for other processes as well. ${ }^{27}$

\section{Results and Discussion}

In continuation of our study of catalytic activity of TMSCl and other organochlorosilanes in the acetalization reaction to synthesize nitroaromatic dithio- and oxathioacetals we have investigated for the first time the interaction of $o, m, p$ - nitrobenzaldehydes with mercaptoethanol without heating in the presence of chlorometylsilanes. It has been found that open-chain bis(2-hydroxyethyl)dithioacetals 3a-c or bicyclic nitrophenyl oxathioacetals 2a-c are generated depending on the ratio of the starting reagents (Scheme 1). 


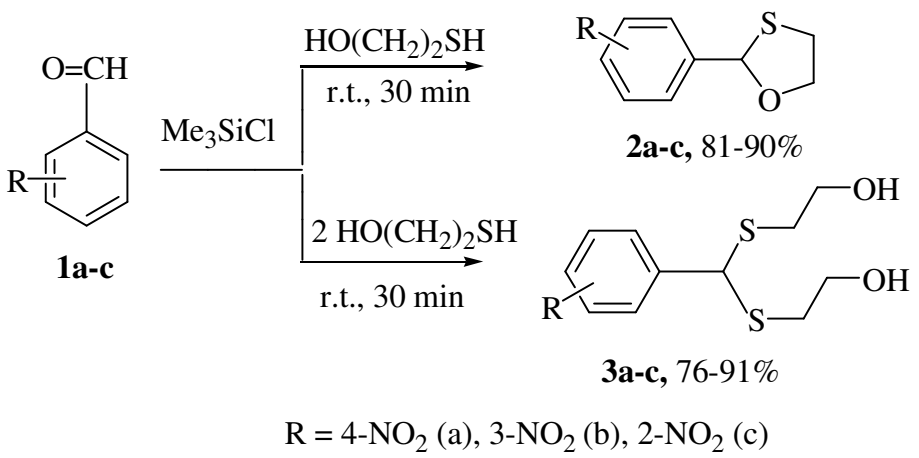

Scheme 1. Synthesis of 1,3-oxathiolanes 2a-c and bis(2-hydroxyethyl)dithioacetals 3a-c.

Using the interaction of 4-nitrobenzaldehyde with 2-mercaptoethanol as an example, we have studied the effect of the catalyst structure and amount, the reaction temperature, the organochlorine solvent nature and the reagents ratio on yields of the target products $\mathbf{2 a}$ and 3a (Table 1).

Table 1. Results of acetalization of 4-nitrobenzaldehyde 1a with 2-mercaptoethanol using chlorosilanes (reaction time $30 \mathrm{~min}$ )

\begin{tabular}{ccccccc}
\hline Entry & $\begin{array}{c}\text { Molar ratio } \\
\mathbf{1 a} / \mathrm{HO}\left(\mathrm{CH}_{2}\right)_{2} \mathrm{SH} / \\
\text { chlorosilane }\end{array}$ & Silane & $\begin{array}{c}\text { Solvent, } \\
\mathrm{mL}\end{array}$ & Temperature, ${ }^{\circ} \mathrm{C}$ & $\begin{array}{c}\text { Yield }^{\mathrm{a}} \\
\mathbf{2 a}(\mathbf{3 a}), \%\end{array}$ & $\begin{array}{c}\text { Selectivity } \\
\mathbf{2 a}{ }^{\mathrm{b}} \mathbf{3 a}\end{array}$ \\
\hline 1 & $1 / 1 / 4$ & $\mathrm{Me}_{3} \mathrm{SiCl}$ & neat & r.t & 88 & $100 / 0$ \\
2 & $1 / 1 / 4$ & $\mathrm{Me}_{3} \mathrm{SiCl}$ & $\mathrm{CH}_{2} \mathrm{Cl}_{2}, 2$ & $35-40$ & 90 & $100 / 0$ \\
3 & $1 / 1 / 4$ & $\mathrm{Me}_{3} \mathrm{SiCl}$ & $\mathrm{CCl}_{4}, 2$ & $60-65$ & 81 & $100 / 0$ \\
4 & $1 / 1 / 4$ & $\mathrm{MeSiCl}_{3}$ & neat & r.t & 67 & $92 / 8$ \\
5 & $1 / 2 / 6$ & $\mathrm{Me}_{3} \mathrm{SiCl}_{2}$ & neat & r.t & $(91)$ & $0 / 100$ \\
6 & $1 / 2 / 4$ & $\mathrm{Me}_{2} \mathrm{SiCl}_{2}$ & neat & r.t & $(87)$ & $7 / 93$ \\
7 & $1 / 2 / 4$ & $\mathrm{Me}_{2} \mathrm{SiCl}_{2}$ & $\mathrm{CH}_{2} \mathrm{Cl} l_{2}, 2$ & $35-40$ & $(90)$ & $0 / 100$ \\
\hline
\end{tabular}

${ }^{a}$ Isolated yield.

${ }^{b}$ Ratios were determined by integration of ${ }^{1} \mathrm{H}$ NMR signals in crude reaction mixture.

The results given in Table 1 demonstrate that 4-nitrobenzaldehyde reacts with 2mercaptoethanol (equimolar ratio of the reagents) at $20-40{ }^{\circ} \mathrm{C}$ for $30 \mathrm{~min}$ under solvent-free conditions or in $\mathrm{CH}_{2} \mathrm{Cl}_{2}$ solution in the presence of TMSCl 4-fold molar excess to afford 1,3oxathiolane $\mathbf{2 a}$ in $88-90 \%$ yields (entry 1,2 ). Under the similar conditions, but with use of $\mathrm{CCl}_{4}$ as a solvent and heating the reaction mixture up to $\left(60-65^{\circ} \mathrm{C}\right)$, the corresponding 1,3oxathiolane $\mathbf{2 a}$ is formed, the yield being $9 \%$ lower than that achieved under solvent-free conditions or in the $\mathrm{CH}_{2} \mathrm{Cl}_{2}$ solution (entry 3). The reaction of the aldehyde 1a with equimolar amount of 2-mercaptoethanol in the presence of trichloro(methyl)silane under solvent-free conditions proceeds with the lesser selectivity to give the target product $\mathbf{2 a}$ in a lower yield (67\%), the impurity of dithioacetal 3a being simultaneously generated (Table 1, entry 4). 
Heating-free reactions of nitrobenzaldehyde 1a with two-fold molar excess of 2mercaptoethanol under the effect of both chlorotrimethylsilane (entry 5) and dichlorodimethylsilane (entry 6) produce bis(2-hydroxyethyl)dithioacetal 3a in the yields of $91 \%$ and $87 \%$, respectively. When four-fold molar excess of dichlorodimethylsilane is employed in the reaction, the bicyclic derivative $\mathbf{2 a}$ is formed in $\approx 7 \%$ yield. At the same time, condensation of the aldehyde 1a with 2-mercaptoethanol in the presence of four-fold molar excess of dichlorodimethylsilane at $35-40{ }^{\circ} \mathrm{C}$ in the $\mathrm{CH}_{2} \mathrm{Cl}_{2}$ solution leads to the selective formation of bis(2-hydroxyethyl)dithioacetal 3a in $90 \%$ yield (entry 7).

Similarly, in the reaction of 2- and 3-nitrobenzaldehydes with 2-mercaptoethanol depending on the starting reagents ratio two types of products are produced, namely, openchain bis(2-hydroxyethyl)dithioacetal $\mathbf{3 b}, \mathbf{c}$ or bicyclic - nitrophenyloxathiolane $\mathbf{2 b , c}$, the yield of the latter being about $89 \%$ (Table 2).

From the results obtained follow that the selectivity of the formation of oxathiolanes or dithioacetals from nitrobenzaldehydes in the presence of $\mathrm{TMSCl}$ is determined mainly by the reagents ratio. The alteration of the reaction temperature from 20 to $40{ }^{\circ} \mathrm{C}$ does not effect the process direction (entries 1, 2, 5, Table 1). Only in the case when the reaction mixture was heated to $65^{\circ} \mathrm{C}$ (entry 3 Table 1 ), the yield of $2 \mathbf{a}$ slightly decreased.

The nature of nitrobenzaldehyde influences insignificantly of the process selectivity. For example, in the case of 3-nitrobenzaldehyde (under optimal conditions of oxathiolane synthesis), ditioacetal was formed in small amounts (NMR, entry 5, Table 2).

Table 2. Synthesis of oxathioacetals 2a-c and dithioacetals 3a-c by reaction of nitrobenzaldehydes 1a-c with 2-mercaptoethanol using TMSCl

\begin{tabular}{ccccccc}
\hline Entry & Aldehyde & $\begin{array}{c}\text { Molar ratio } \\
\text { 1/HO(CH} \\
\text { H/ TMSCl }\end{array}$ & Method & Product & Yield $^{\text {c }}$ (\%) & Selectivity 2:3 \\
\hline 1 & $\mathbf{1 a}$ & $1 / 1 / 4$ & $\mathrm{~A}$ & $\mathbf{2 a}$ & 88 & $100 / 0$ \\
2 & $\mathbf{1 a}$ & $1 / 1 / 4$ & $\mathrm{~B}$ & $\mathbf{2 a}$ & 90 & $100 / 0$ \\
$3^{\mathrm{b}}$ & $\mathbf{1 a}$ & $1 / 1 / 4$ & $\mathrm{~B}$ & $\mathbf{2 a}$ & 81 & $100 / 0$ \\
4 & $\mathbf{1 a}$ & $1 / 2 / 6$ & $\mathrm{~A}$ & $\mathbf{3 a}$ & 91 & $0 / 100$ \\
5 & $\mathbf{1 b}$ & $1 / 1 / 4$ & $\mathrm{~A}$ & $\mathbf{2 b}$ & 85 & $98 / 5$ \\
6 & $\mathbf{1 b}$ & $1 / 2 / 6$ & $\mathrm{~A}$ & $\mathbf{3 b}$ & 76 & $2 / 98$ \\
7 & $\mathbf{1 b}$ & $1 / 2 / 4$ & $\mathrm{~B}$ & $\mathbf{3 b}$ & 84 & $0 / 100$ \\
8 & $\mathbf{1 c}$ & $1 / 1 / 4$ & $\mathrm{~A}$ & $\mathbf{2 c}$ & 83 & $100 / 0$ \\
9 & $\mathbf{1 c}$ & $1 / 2 / 6$ & $\mathrm{~A}$ & $\mathbf{3 c}$ & 89 & $0 / 100$ \\
\hline
\end{tabular}

${ }^{a}$ Reaction conditions. A: r.t., 30 min., neat; B: $35-40{ }^{\circ} \mathrm{C}, 30$ min., $\mathrm{CH}_{2} \mathrm{Cl}_{2}$.

${ }^{\mathrm{b}}$ Reaction was carried out in $\mathrm{CCl}_{4}\left(60-65^{\circ} \mathrm{C}\right)$.

${ }^{\mathrm{c}}$ Isolated yield.

Bis(2-hydroxyethyl)dithioacetals are synthesized also from nitrobenzaldehydes 1a-c and two-fold excess of 2-mercaptoethanol under the effect of dichlorodimethylsilane in the 
$\mathrm{CH}_{2} \mathrm{Cl}_{2}$ solution or without it. Scheme shows a possible way of dithioacetals 3a-c formation (Scheme 2).

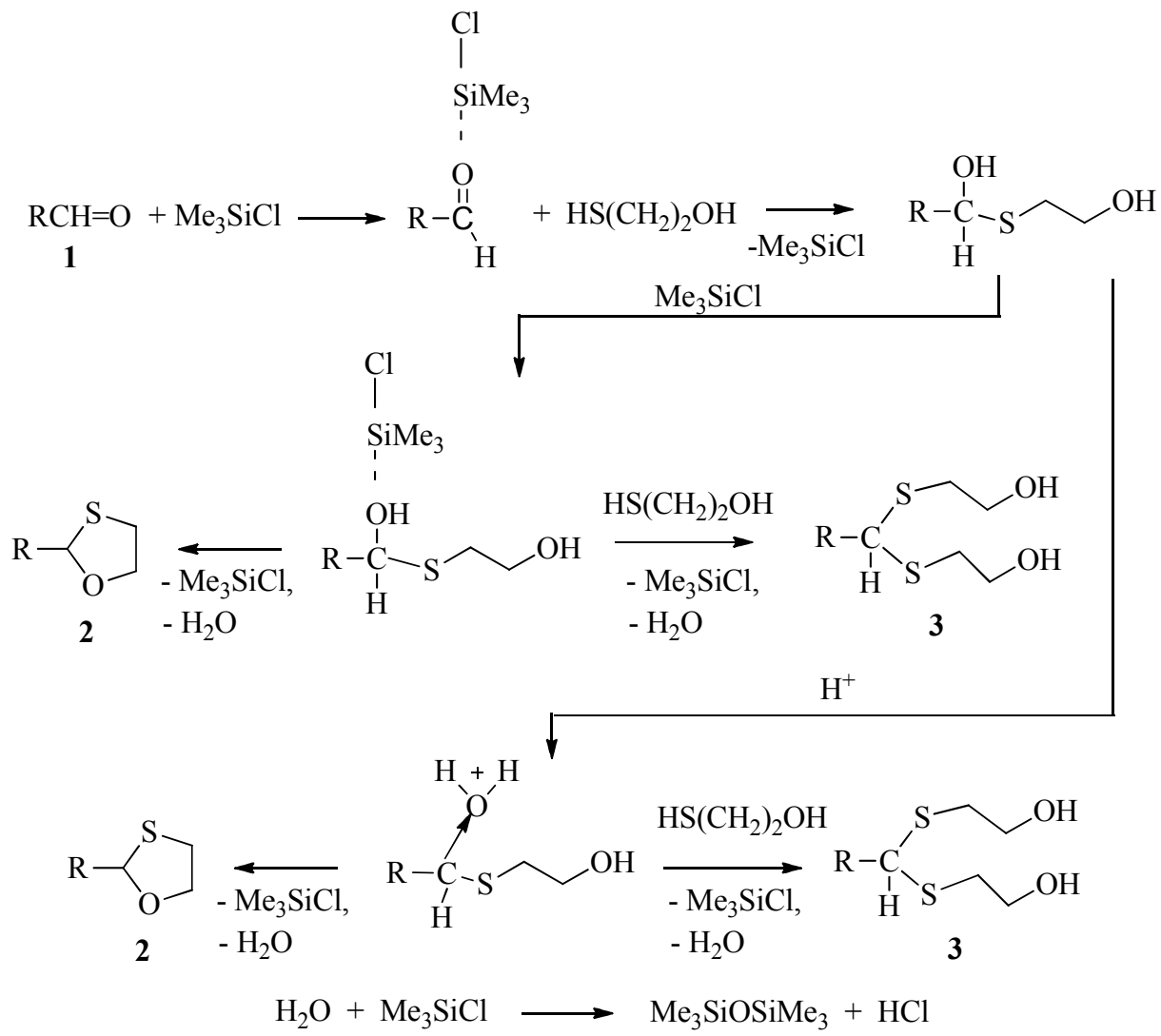

Scheme 2. A possible way of dithioacetals $\mathbf{3}$ and oxathiolanes $\mathbf{2}$ formation.

Chlorotrimethylsilane plays a role of an effective water scavenger. In this reaction, $\mathrm{Me}_{3} \mathrm{SiCl}$ shows likely the properties of Lewis acid, the complex formed at the first step being further transformed to the adduct of mercaptoalcohol (Scheme 2). ${ }^{27}$

The formation of $\alpha$-chlorothioether $\mathrm{HOCH}_{2} \mathrm{CH}_{2} \mathrm{SCHRCl}$, previously reported for the reaction of formaldehyde with thiols is also probable. ${ }^{28}$ The further reaction of this ether according to HSAB concept furnishes the target dithioacetals.

So far, it was reported only one precedent of bis(2-hydroxyethyl)dithioacetal (3b) formation (in $90 \%$ yield) by the reaction of aldehyde (1b) with the two-fold excess of 2mercaptoethanol. ${ }^{29}$ In this case, the acetalization occurred in the presence of $\mathrm{NaHSO}_{4}-\mathrm{SiO}_{2}$ as a catalyst at room temperature and under solvent-free conditions. ${ }^{29}$ The authors assume that this reaction, exclusively proceeding via the SH-group to give bis(2hydroxyethyl)dithioacetal (instead the expected 1,3-oxathiolane), is apparently due to the stabilization effect of the $\mathrm{OH}$ group owing to its stronger hydrogen-bonding with the sylanol groups of silica gel.

It should be emphasized once again that the synthesis of dithioacetal 3a-c was sometimes accompanied by the formation of 1,3-oxathiolane 2a-c. Compounds $\mathbf{2 a - c}$ were obtained in a 
minor amount along with the target compounds 3a-c, the ratio of the initial reagents being 1:2 (Table 1, 2).

The contradictory data were given in the paper $^{30}$ where it was reported that the 4nitrobenzaldehyde reacted with 2-mercaptoethanol under solvent-free conditions in the presence of silica-supported perchloric acid to produce only 1,3-oxathiolane derivative 2a even under $20 \%$ mercaptoethanol excess.

The authors of the paper $^{31}$ have developed a procedure for chemoselective bisthioacetalization of carbonyl compounds by alkyl- and arylmercaptans, including the 4chlorobenzaldehyde by 2-mercaptoethanol to give bis(hydroxy)dithioacetal - 2,2'-((4chlorophenyl)methylene)-bis(sulfanediyl)diethanol in $93 \%$ yield. The reaction was carried out under solvent-free conditions using $10 \mathrm{~mol} \%$ cerium triflate $\mathrm{Ce}(\mathrm{OTf})_{3}$ as a recyclable catalyst. Unfortunately the authors did not give data concerning the influence of mercaptoethanol/carbonyl compound ratio on direction of the process. Probably, the interaction of the reagents taken in equimolar ratio under the same conditions and even in the presence of $\mathrm{Ce}(\mathrm{OTf})_{3}$ would afford 2-(4-chlorophenyl)-1,3-oxathiolane. To confirm the process hemoselectivity, it seems to be appropriate to study the influence of the reagents ratio upon the products composition and structure.

At the same time it has been reported ${ }^{32}$ that the reaction of 4-nitrobenzaldehyde and 2mercaptoethanol (1:1.5 ratio) at room temperature in the presence of $\mathrm{Yb}(\mathrm{OTf})_{3}(0.01-0.05$ equiv) in ionic liquids $[\mathrm{bmim}][\mathrm{Br}],[\mathrm{bmim}]\left[\mathrm{BF}_{4}\right]$ and $[\mathrm{bmim}]\left[\mathrm{PF}_{6}\right]$ furnishes the corresponding 2-substituted 1,3-oxathiolane in $98 \%$ yield. Thus, it has been shown ${ }^{31,32}$ that the direction of the reaction between aromatic aldehydes and 2-mercaptoethanol only depends on the reaction conditions while the reagent ratio is unlikely to be determining factor. We have found that in the reaction of aldehydes with 2-mercaptoethanol in the presence of $\mathrm{TMSCl}$, the initial reagents ratio plays crucial role for the products structure.

The studies of properties of the products synthesized have allowed us to conclude for the first time that bis(2-hydroxyethyl)dithioacetal 3a-c undergoes the unexpected spontaneous transformation to the oxathiolane cycle with the elimination of mercaptoalcohol after two months standing at room temperature. So, according the NMR data, a mixture of oxathioacetal $\mathbf{2 c}$ and dithioacetal $\mathbf{3 c}$ (ratio $\mathbf{2 c}: \mathbf{3 c}=1: 9$ ), after 60 days of air-free standing, is converted to a mixture with a ratio of $\mathbf{2 c}: \mathbf{3 c}$ equaling to $10: 1$. The conversion of dithioacetal 3c into five-membered oxathioacetal cycle (compound 2c) results in inversion of chemical shifts of the aromatic ring protons at the position 3,6 (from 7.85 to 8.04 ppm for H-3, and from 8.01 to $7.89 \mathrm{ppm}$ for $\mathrm{H}-6$ ) and low-field shift of the carbon signals of the phenyl ring $\mathrm{C}$ 1 and C-2, C-6. The similar transformation of dithioacetal $3 \mathbf{c}$ to oxathiolane $2 \mathbf{c}$ occurs under heating of the former at the $\mathrm{CCl}_{4}$ solution in the presence of $\mathrm{Me}_{3} \mathrm{SiCl}$ at $60-65{ }^{\circ} \mathrm{C}$, after $2 \mathrm{~h}$ heating the ratio 3c:2c reaching 92:8. Interestingly, we have not observed the reversed transformation of nitrophenylsubstituted 1,3-oxathiolane 2a-c into the open-chain bis(2hydroxyethyl)dithioacetals 3a-c during a long keeping of compounds 2a-c under moisture presence conditions.

The synthesized acetals are either crystal substances (2a, c; 3a, c) or light-yellow viscous oils $(\mathbf{2} \mathbf{b}, \mathbf{3 b})$. The analysis of mass-spectra of 1,3-oxathiolanes $\mathbf{2 a - c}$ under the electron and chemical ionization conditions has shown that the major direction of fragmentation of 
molecular ions in compounds $\mathbf{2}$ is due to the cleavage of the heterocyclic ring, the charge and not-paired electron being mainly localized on the $\left[\mathrm{C}_{2} \mathrm{H}_{4} \mathrm{~S}\right]^{+}$fragment with $\mathrm{m} / \mathrm{z}=60\left(\mathrm{I}_{\text {rel. }}=\right.$ $100 \%$ in all the spectra) (Scheme 3).

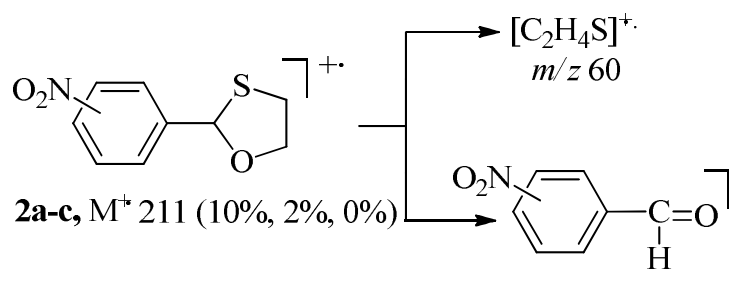

$m / z$ 151: 3\%(2a), 19\%(2b), 93\%(2c)

\section{Scheme 3}

The further fragmentation of ion with $\mathrm{m} / \mathrm{z} 151$ for $o$-isomer $\mathbf{2 c}$ is due to the consecutive elimination of NO (ion with $\mathrm{m} / z 121$ (37\%) and CO (ion with $\mathrm{m} / z 93(12 \%)$ molecules. In the mass-spectrum of $m$-isomer $\mathbf{2 b}$, these peaks are less intensive $(19 \%, 21 \%$ and $<1 \%)$, while for $p$-isomer $\mathbf{2 a}$ they are absent at all.

The comparison of the mass spectra of isomeric nitro-derivatives of 1,3-oxathiolanes 2a-c evidences the "ortho-effect", i.e., the ion peak $[\mathrm{M}-\mathrm{OH}]^{+}$with $m / z 194$ (6) and the corresponding peaks of the $[\mathrm{M}-\mathrm{OH}-\mathrm{CO}]^{+}$and $[\mathrm{M}-\mathrm{OH}-\mathrm{NO}]^{+}$ions with $\mathrm{m} / \mathrm{z}, 166(17 \%)$ and $136(47 \%)$, which are typical for the ortho-substituted aromatic nitro compounds, are observable in the spectrum of 2c. The analysis of the mass spectra of 1,3-dioxa- and 1,3oxathiolane nitro-derivatives has revealed that the sulfur atom in the saturated cycle plays the crucial role in the molecular ion fragmentation under the electronic ionization. For example, in the course of 1,3-oxathiolane degradation, the direction related to the nitro group decomposition (typical for 1,3-dioxalane) is suppressed completely. Also, the ion peak with $\mathrm{m} / \mathrm{z} 89$ corresponding to the oxathiolane fragment (ion with $\mathrm{m} / \mathrm{z} 73$ for dioxalane) is almost absent. While recording the mass-spectra, compounds 3a-c undergo thermal destruction. The spectra of thermolysis products coincide with those of 1,3-oxathiolanes 2a-c that supports the more thermodynamic stability of 1,3-oxathiolanes as compared to bis(2hydroxyethyl)dithioacetal (3a-c).

\section{Conclusions}

In conclusion, we have devised a simple and efficient protocol for the preparation of bis(2hydroxyethyl)dithioacetals and 1,3-oxathiolanes from nitrobenzaldehydes and 2mercaptoethanol in the presence of $\mathrm{TMSCl}$ and dichlorodimethylsilane. It has been established that the dominating direction of the reaction between nitrobenzaldehydes and 2mercaptoethanol in the presence of chlorosilanes is determined the reagents ratio. The facile transformation of bis(2-hydroxyethyl)dithioacetals into the corresponding 1,3-oxathiolanes accompanied by the elimination of mercaptoalcohol on long-term standing without external 
action has been shown. The similar transformation has been observed under electronic and chemical ionization of dithioacetals during analysis of their mass spectra. This fact indicates thermodynamic instability of these compounds.

\section{Experimental Section}

General. NMR spectra were recorded on a Bruker DPX-400 spectrometer $\left({ }^{1} \mathrm{H}, 400.13 \mathrm{MHz}\right.$. $\left.{ }^{13} \mathrm{C}, 100.61\right)$ in $\mathrm{CDCl}_{3}, \mathrm{CD}_{3} \mathrm{OD}$ as the solvents, and HMDS as internal standard. Chemical shifts are reported in ppm values $(\delta)$ and coupling constants $(J)$ in Hertz. IR spectra were run on a Bruker Vertex 70 instrument. Mass-spectra under electronic ionization were recorded with Shimadzu GCMS-QP5050A spectrometer (quadrupole mass-analyzer, mass-detection range is 34-650 Да) using the direct input sample system into ion source. The process temperature was varied from 30 to 200 degrees depending on sample fugitiveness. The spectra under chemical ionization were recorded on Agilent $5975 \mathrm{C}$ instrument using methane as the reagent gas. Melting points were measured on a Kofler melting-point apparatus and uncorrected. Elemental analyses for $\mathrm{C}, \mathrm{H}$ and $\mathrm{N}$ were obtained using a Thermo Finnigan Flash series1112 EA analyzer. Aldehydes, 1,2-mercaptoethanol and chlorosilanes were sourced commercially and were used in the reactions without additional purification. Solvents were purified, if necessary, by standard methods.

General procedure for the preparations of 1,3-Oxathiolanes (2a-c) and bis(2hydroxyethyl)dithioacetale (3a-c)

Method (a). To a stirred mixture of nitrobenzaldehyde 1 ( $0.756 \mathrm{~g}, 5.0 \mathrm{mmol})$ and TMSCl $(2.57 \mathrm{~mL}, 20.0 \mathrm{mmol})$ was added dropwise 2-mercaptoethanol $(0.39 \mathrm{~g}, 5.0 \mathrm{mmol})$ at r.t. The reaction was accompanied by self-heating and separation of the mixture into two layers. After stirring at r.t. for $30 \mathrm{~min}$ volatiles were removed from the reaction mixture under vacuum. Then the crude product was purified by recrystallization with hexane $(\mathbf{2 a}, \mathbf{c})$ or washed with hexane and concentrated under reduced pressure (2b) (Table 2).

Method (в). To a solution of aldehyde 1 (0.756 g, $5.0 \mathrm{mmol})$ in $\mathrm{CH}_{2} \mathrm{Cl}_{2}(2 \mathrm{ml})$, TMSCl (2.57 $\mathrm{mL}, 20 \mathrm{mmol})$ and 2-mercaptoethanol $(0.39 \mathrm{~g}, 5 \mathrm{mmol})$ were added under stirring at r.t. The reaction mixture was at $35-40{ }^{\circ} \mathrm{C}$ stirred for $30 \mathrm{~min}$ and then vacuumized. The residue obtained was recrystallized from hexane and dried in vacuo to afford the corresponding products 2a-c. In the case of dithioacetalization, the reaction was carried out under the same conditions (method (а) (в)) using $0.78 \mathrm{~g}$ of 2-mercaptoethanol $(10 \mathrm{mmol})$. After stirring for $30 \mathrm{~min}$, volatiles were removed from the reaction mixture under vacuum and the residue was treated with diethyl ether for the crystallization of a product. The latter was filtreated, washed with hexane and dried under reduced pressure to furnish the desired bis(2hydroxyethyl)dithioacetals 3a-c (Table 2).

2-(4-Nitrophenyl)-1,3-oxathiolane (2a). White crystals, yield 88\%, $0.93 \mathrm{~g}, \mathrm{mp} \mathrm{81-83}{ }^{\circ} \mathrm{C}$ (Lit. ${ }^{30} \mathrm{mp} 78{ }^{\circ} \mathrm{C}$, Lit. $\left.^{21} \mathrm{mp} 82.5-84{ }^{\circ} \mathrm{C}\right)$. IR (KBr, $\left.v_{\max }, \mathrm{cm}^{-1}\right): 3112 \mathrm{w}\left(\mathrm{C}-\mathrm{H}_{\mathrm{ar}}\right), 2945,2888 \mathrm{w}$ $\left(\mathrm{C}-\mathrm{H}_{\mathrm{alk}}\right), 1603 \mathrm{~m}\left(\mathrm{C}=\mathrm{C}_{\mathrm{ar}}\right), 1521,1345$ vs $\left(\mathrm{NO}_{2}\right) .{ }^{1} \mathrm{H}$ NMR $\left(\mathrm{CDCl}_{3}\right), \delta_{\mathrm{H}}=3.21(\mathrm{ddd}, 1 \mathrm{H}$, $\left.\mathrm{CH}_{2} \mathrm{~S},{ }^{2} J=10.0,{ }^{3} J=6.4,{ }^{3} J=3.5 \mathrm{~Hz}\right), 3.26\left(\mathrm{ddd}, \mathrm{H}, \mathrm{CH}_{2} \mathrm{~S},{ }^{2} J=10.0,{ }^{3} J=9.1,{ }^{3} J=6.1 \mathrm{~Hz}\right.$ ), 
$4.01\left(\mathrm{ddd}, 1 \mathrm{H}, \mathrm{CH}_{2} \mathrm{O},{ }^{2} J=9.1,{ }^{3} J=9.1,{ }^{3} J=6.4 \mathrm{~Hz}\right.$ ), $4.53\left(\mathrm{ddd}, 1 \mathrm{H}, \mathrm{CH}_{2} \mathrm{O},{ }^{2} J=9.1,{ }^{3} J=6.1\right.$, ${ }^{3} J=3.5 \mathrm{~Hz}$ ), 6.10 (s, 1H, OCHS), 7.58 (d, 2H, CH $\left.(2,6),{ }^{3} J=8.7 \mathrm{~Hz}\right), 8.19$ (d, 2H, CH $(3,5)$, $\left.{ }^{3} J=8.7 \mathrm{~Hz}\right) \cdot{ }^{13} \mathrm{C} \mathrm{NMR}\left(\mathrm{CDCl}_{3}\right), \delta_{\mathrm{C}}=34.17\left(\mathrm{CH}_{2} \mathrm{~S}\right), 72.48\left(\mathrm{CH}_{2} \mathrm{O}\right), 85.49$ (OCHS), 123.78 $(\mathrm{C}-3,5), 127.23$ (C-2,6), 147.08 (C-1), 147.94 (C-4). MS (E.I, $70 \mathrm{eV}): \mathrm{m} / \mathrm{z}(\%)=211(10$ $[M]^{+*}$ ), 151 (19), 150 (8), 135 (3), 134 (3), 105 (9), 104 (5), 89 (8), 77 (16), 76 (9), 75 (5), 65 (3), 63 (7), 62 (11), 61 (19), 60 (100), 59 (41), 58 (5), 51 (22), 50 (13). Anal. Calcd for $\mathrm{C}_{9} \mathrm{H}_{9} \mathrm{NO}_{3} \mathrm{~S}$ (211.23): C, 51.17; H, 4.29; N, 6.63; S, 15.18. Found: C, 51.25; H, 4.37; N, 6.64; S, 15.11 .

2-(3-Nitrophenyl)-1,3-oxathiolane (2b). Light-yellow crystals, yield 85\%, 0.90g, mp 49-50 ${ }^{\circ} \mathrm{C}$ (Lit. ${ }^{33} \mathrm{mp} 51-52{ }^{\circ} \mathrm{C}$ ). IR (neat, $\left.v_{\max }, \mathrm{cm}^{-1}\right)$ : $3088 \mathrm{~m}\left(\mathrm{C}-\mathrm{H}_{\mathrm{ar}}\right), 2942,2874 \mathrm{~s}\left(\mathrm{C}-\mathrm{H}_{\mathrm{alk}}\right), 1615$, $1584 \mathrm{w}\left(\mathrm{C}=\mathrm{C}_{\mathrm{ar}}\right), 1529,1352$ vs $\left(\mathrm{NO}_{2}\right) .{ }^{1} \mathrm{H}$ NMR $\left(\mathrm{CDCl}_{3}\right), \delta_{\mathrm{H}}=3.21\left(\mathrm{ddd}, 1 \mathrm{H}, \mathrm{CH}_{2} \mathrm{~S},{ }^{2} J=9.0\right.$, ${ }^{3} J=6.0,{ }^{3} J=3.3 \mathrm{~Hz}$ ), $3.27\left(\mathrm{ddd}, 1 \mathrm{H}, \mathrm{CH}_{2} \mathrm{~S},{ }^{2} J=9.0,{ }^{3} J=8.8,{ }^{3} J=6.0 \mathrm{~Hz}\right.$ ), 3.99 (ddd, $1 \mathrm{H}$, $\left.\mathrm{CH}_{2} \mathrm{O},{ }^{2} \mathrm{~J}=9.0,{ }^{3} \mathrm{~J}=6.0,{ }^{3} \mathrm{~J}=3.3 \mathrm{~Hz}\right), 4.53\left(\mathrm{ddd}, 1 \mathrm{H}, \mathrm{CH}_{2} \mathrm{O},{ }^{2} \mathrm{~J}=9.0,{ }^{3} \mathrm{~J}=8.8,{ }^{3} \mathrm{~J}=6.0 \mathrm{~Hz}\right)$, $6.10(\mathrm{~s}, 1 \mathrm{H}, \mathrm{OCHS}), 7.50\left(\mathrm{t}, 1 \mathrm{H}, \mathrm{CH}(5){ }^{3} J_{5-6}=8.1,{ }^{3} J_{5-4}=8.1 \mathrm{~Hz}\right), 7.73\left(\mathrm{~d}, 1 \mathrm{H}, \mathrm{CH}(6),{ }^{3} J_{6-5}\right.$ $=8.1 \mathrm{~Hz}), 8.14\left(\mathrm{~d}, 1 \mathrm{H}, \mathrm{CH}(4),{ }^{3} J_{4-5}=8.1 \mathrm{~Hz}\right), 8.30\left(\mathrm{t}, 1 \mathrm{H}, \mathrm{CH}(2),{ }^{4} J_{2-4}=1.6,{ }^{4} J_{2-6}=1.6 \mathrm{~Hz}\right)$. ${ }^{13} \mathrm{C} \mathrm{NMR}\left(\mathrm{CDCl}_{3}\right), \delta_{\mathrm{C}}=34.13\left(\mathrm{CH}_{2} \mathrm{~S}\right), 72.32\left(\mathrm{CH}_{2} \mathrm{O}\right), 85.51(\mathrm{OCHS}), 121.65(\mathrm{C}-2), 123.40$ (C-4), 129.42 (C-5), 132.62 (C-6), 142.11 (C-1), 148.35 (C-3). MS (E.I, $70 \mathrm{eV}): \mathrm{m} / \mathrm{z}(\%)=$ $211\left(<1[M]^{+*}\right), 194(8), 166(17), 164(7), 152$ (8), 151 (93), 138 (6), 137 (4), 136 (47), 135 (7), 134 (8), 123 (3), 122 (5), 121 (37), 119 (6), 109 (4), 108 (9), 105 (4), 104 (12), 93 (12), 92 (6), 91 (7), 89 (5), 79 (8), 78 (5), 77 (27), 76 (19), 75 (6), 74 (6), 69 (4), 65 (23), 64 (9), 63 (11), 62 (10), 61 (21), 60 (100), 59 (51), 58 (8), 52 (13), 51 (50), 50 (29). Anal. Calcd for $\mathrm{C}_{9} \mathrm{H}_{9} \mathrm{NO}_{3} \mathrm{~S}$ (211.23): C, 51.17; H, 4.29; N, 6.63; S, 15.18. Found: C, 51.23; H, 4.36; N, 6.62; $\mathrm{S}, 15.11$.

2-(2-Nitrophenyl)-1,3-oxathiolane (2c). Light-yellow crystals, yeild 83\%, $0.88 \mathrm{~g}, \mathrm{mp}$ 60-61 ${ }^{\circ} \mathrm{C}\left(\mathrm{Lit}^{34} \mathrm{mp} 57.5-60{ }^{\circ} \mathrm{C}\right)$. IR (KBr, $\left.v_{\max }, \mathrm{cm}^{-1}\right)$ : $3103 \mathrm{w}\left(\mathrm{C}-\mathrm{H}_{\mathrm{ar}}\right), 2940,2893 \mathrm{w}\left(\mathrm{C}-\mathrm{H}_{\mathrm{alk}}\right), 1607$, $1577 \mathrm{~m}\left(\mathrm{C}=\mathrm{C}_{\mathrm{ar}}\right), 1517,1349$ vs $\left(\mathrm{NO}_{2}\right) .{ }^{1} \mathrm{H} \mathrm{NMR}\left(\mathrm{CDCl}_{3}\right), \delta_{\mathrm{H}}=3.11\left(\mathrm{ddd}, 1 \mathrm{H}, \mathrm{CH}_{2} \mathrm{~S},{ }^{2} J=\right.$ $\left.10.3,{ }^{3} J=5.8,{ }^{3} J=3.1 \mathrm{~Hz}\right), 3.15\left(\mathrm{ddd}, 1 \mathrm{H}, \mathrm{CH}_{2} \mathrm{~S},{ }^{2} J=10.3,{ }^{3} J=9.2,{ }^{3} J=5.8 \mathrm{~Hz}\right.$ ), 4.04 (ddd, $\left.1 \mathrm{H}, \mathrm{CH}_{2} \mathrm{O},{ }^{2} \mathrm{~J}=9.2,{ }^{3} \mathrm{~J}=9.2,{ }^{3} \mathrm{~J}=5.8 \mathrm{~Hz}\right), 4.58\left(\mathrm{ddd}, 1 \mathrm{H}, \mathrm{CH}_{2} \mathrm{O},{ }^{2} \mathrm{~J}=9.2,{ }^{3} \mathrm{~J}=5.8,{ }^{3} \mathrm{~J}=3.1\right.$ $\mathrm{Hz}), 6.57$ (s, 1H, OCHS), $7.44\left(\mathrm{ddd}, 1 \mathrm{H}, \mathrm{CH}(4),{ }^{3} J_{4-3}=8.2,{ }^{3} J_{4-5}=7.6,{ }^{4} J_{4-6}=1.5 \mathrm{~Hz}\right), 7.64$ $\left(\mathrm{ddd}, 1 \mathrm{H}, \mathrm{CH}(5),{ }^{3} J_{5-6}=8.0,{ }^{3} J_{5-4}=7.6,{ }^{4} J_{5-3}=1.0 \mathrm{~Hz}\right), 7.86\left(\mathrm{dd}, 1 \mathrm{H}, \mathrm{CH}(6),{ }^{3} J_{6-5}=8.0,{ }^{4} J_{6-4}\right.$ $=1.5 \mathrm{~Hz}), 8.02\left(\mathrm{dd}, 1 \mathrm{H}, \mathrm{CH}(3),{ }^{3} J_{3-4}=8.2,{ }^{4} J_{3-5}=1.0 \mathrm{~Hz}\right) .{ }^{13} \mathrm{C} \mathrm{NMR}\left(\mathrm{CDCl}_{3}\right), \delta_{\mathrm{C}}=33.24$ $\left(\mathrm{CH}_{2} \mathrm{~S}\right), 72.71\left(\mathrm{CH}_{2} \mathrm{O}\right), 82.03(\mathrm{OCHS}), 124.77(\mathrm{C}-3), 127.34$ (C-6), $128.73(\mathrm{C}-4), 133.96(\mathrm{C}-$ 5), 137.63 (C-1), 148.83 (C-2). MS (E.I, $70 \mathrm{eV}): \mathrm{m} / \mathrm{z}(\%): 211\left(2\left[\mathrm{M}^{+\bullet}\right), 151\right.$ (3), 150 (3), 105 (3), 104 (5), 93 (2), 92 (3), 89 (5), 78 (5), 77 (18), 76 (9), 75 (8), 74 (8), 69 (3), 65 (5), 64 (3), 63 (11), 62 (12), 61 (14), 60 (100), 59 (35), 58 (9), 52 (3), 51 (38), 50 (26). Anal. Calcd for $\mathrm{C}_{9} \mathrm{H}_{9} \mathrm{NO}_{3} \mathrm{~S}$ (211.23): C, 51.17; H, 4.29; N, 6.63; S, 15.18. Found: C, 51.29; H, 4.32; N, 6.64; S, 15.14 .

2,2'-\{[(4-Nitrophenyl)methanediyl]disulfanediyl $\}$ diethanol (3a). White crystals, yield 91\%, $1.31 \mathrm{~g}, \mathrm{mp} 83-85^{\circ} \mathrm{C}$. IR (vaseline oil, $v_{\max }, \mathrm{cm}^{-1}$ ): $3284 \mathrm{w}(\mathrm{OH}), 1517,1344 \mathrm{~s}\left(\mathrm{NO}_{2}\right) .{ }^{1} \mathrm{H}$ NMR $\left(\mathrm{CDCl}_{3}\right), \delta_{\mathrm{H}}=2.20(\mathrm{~s}, 2 \mathrm{H}, 2 \mathrm{OH}), 2.69\left(\mathrm{dt}, 2 \mathrm{H}, \mathrm{CH}_{2} \mathrm{~S},{ }^{2} \mathrm{~J}=14.3,{ }^{3} \mathrm{~J}=5.7 \mathrm{~Hz}\right), 2.87(\mathrm{dt}$, $\left.2 \mathrm{H}, \mathrm{CH}_{2} \mathrm{~S},{ }^{2} \mathrm{~J}=14.3,{ }^{3} \mathrm{~J}=5.7 \mathrm{~Hz}\right), 3.80\left(\mathrm{t}, 4 \mathrm{H}, 2 \mathrm{CH}_{2} \mathrm{O},{ }^{3} \mathrm{~J}=5.7 \mathrm{~Hz}\right), 5.24$ (s, $\left.1 \mathrm{H}, \mathrm{SCHS}\right)$, $7.63\left(\mathrm{~d}, 2 \mathrm{H}, \mathrm{CH}(2,6),{ }^{3} \mathrm{~J}=8.8 \mathrm{~Hz}\right), 8.20\left(\mathrm{~d}, 2 \mathrm{H}, \mathrm{CH}(3,5),{ }^{3} \mathrm{~J}=8.8 \mathrm{~Hz}\right) .{ }^{13} \mathrm{C} \mathrm{NMR}\left(\mathrm{CDCl}_{3}\right)$, $\delta_{\mathrm{C}}=35.50\left(\mathrm{CH}_{2} \mathrm{~S}\right), 52.68(\mathrm{SCS}), 61.87\left(\mathrm{OCH}_{2}\right), 124.09(\mathrm{C}-3,5), 128.78(\mathrm{C}-2,6), 147.59$, 
147.78 (C-1,4). Anal. Calcd for $\mathrm{C}_{11} \mathrm{H}_{15} \mathrm{NO}_{4} \mathrm{~S}_{2}$ (289.37): C, 45.66; H, 5.22; N, 4.84; S, 22.16. Found: C, 45.48; H, 5.21; N, 4.82; S, 22.24.

2,2'-\{[(3-Nitrophenyl)methanediyl]disulfanediyl $\}$ diethanol (3b). Light-yellow viscous oil, yield $76 \%, 1.09 \mathrm{~g}$. IR (neat, $\left.v_{\max }, \mathrm{cm}^{-1}\right): 3363 \mathrm{~s}, 1530,1351 \mathrm{~s}\left(\mathrm{NO}_{2}\right) .{ }^{1} \mathrm{H} \mathrm{NMR}\left(\mathrm{CDCl}_{3}\right): \delta=$ 2.43 (br s, 2H, $2 \mathrm{OH}), 2.69\left(\mathrm{dt}, 2 \mathrm{H}, \mathrm{CH}_{2} \mathrm{~S},{ }^{2} \mathrm{~J}=14.1,{ }^{3} \mathrm{~J}=5.6 \mathrm{~Hz}\right), 2.88\left(\mathrm{dt}, 2 \mathrm{H}, \mathrm{CH}_{2} \mathrm{~S},{ }^{2} J=\right.$ $\left.14.1,{ }^{3} J=5.6 \mathrm{~Hz}\right), 3.81\left(\mathrm{t}, 4 \mathrm{H}, 2 \mathrm{CH}_{2} \mathrm{O},{ }^{3} J=5.6 \mathrm{~Hz}\right.$ ), 5.29 (s, 1H, SCHS), 7.53 (t, 1H, CH (5), $\left.{ }^{3} J=8.0 \mathrm{~Hz}\right), 7.83\left(\mathrm{~d}, 1 \mathrm{H}, \mathrm{CH}(6),{ }^{3} J=7.6 \mathrm{~Hz}\right), 8.15\left(\mathrm{dd}, 1 \mathrm{H}, \mathrm{CH}(4),{ }^{3} J=8.0,{ }^{4} J=1.6 \mathrm{~Hz}\right)$, 8.32 (br t, $\left.1 \mathrm{H}, \mathrm{CH}(2),{ }^{4} J=1.6 \mathrm{~Hz}\right) .{ }^{13} \mathrm{C} \mathrm{NMR}\left(\mathrm{CDCl}_{3}\right), \delta_{\mathrm{C}}=35.35\left(\mathrm{CH}_{2} \mathrm{~S}\right), 52.43$ (SCS), $61.89\left(\mathrm{OCH}_{2}\right), 122.85$ (C-2), 123.18 (C-4), 129.81 (C-5), 134.05 (C-6), 142.89 (C-1), 148.28 (C-3). Anal. Calcd for $\mathrm{C}_{11} \mathrm{H}_{15} \mathrm{NO}_{4} \mathrm{~S}_{2}$ (289.37): C, 45.66; H, 5.22; N, 4.84; S, 22.16. Found: C, 45.58; H, 5.24; N, 4.86; S, 22.09.

2,2'-\{[(2-Nitrophenyl)methanediyl]disulfanediyl\}diethanol (3c). White crystals Yield $89 \%, 1.28 \mathrm{~g}$, mp 57-58 ${ }^{\circ} \mathrm{C}$. IR (vaseline oil, $\left.v_{\max }, \mathrm{cm}^{-1}\right): 3255 \mathrm{w}(\mathrm{OH}), 1520,1352 \mathrm{~s}\left(\mathrm{NO}_{2}\right)$. ${ }^{1} \mathrm{H} \mathrm{NMR}\left(\mathrm{CDCl}_{3}\right): \delta_{\mathrm{H}}=2.34(\mathrm{br} \mathrm{s}, 2 \mathrm{H}, 2 \mathrm{OH}) ; 2.72\left(\mathrm{dt}, 2 \mathrm{H}, \mathrm{CH}_{2} \mathrm{~S},{ }^{2} J=14.2,{ }^{3} J=6.2 \mathrm{~Hz}\right)$, 2.87 (dt, $2 \mathrm{H}, \mathrm{CH}_{2} \mathrm{~S},{ }^{2} \mathrm{~J}=14.2,{ }^{3} \mathrm{~J}=6.2 \mathrm{~Hz}$ ), 3.78 (br t, $4 \mathrm{H}, 2 \mathrm{CH}_{2} \mathrm{O},{ }^{3} J=6.2 \mathrm{~Hz}$ ), 5.93 (s, $1 \mathrm{H}$, SCHS), 7.42 (t, 1H, CH (5) J=8.0 Hz), 7.63 (t, 1H, CH (4) J=8.0 Hz), 7.84 (d, 1H, CH (6), $\left.{ }^{3} J=8.0 \mathrm{~Hz}\right), 8.01\left(\mathrm{~d}, 1 \mathrm{H}, \mathrm{CH}(3),{ }^{3} J=8.0 \mathrm{~Hz}\right) \cdot{ }^{13} \mathrm{C} \mathrm{NMR}\left(\mathrm{CDCl}_{3}\right), \delta_{\mathrm{C}}=35.65\left(\mathrm{CH}_{2} \mathrm{~S}\right), 47.16$ (SCS), $61.48\left(\mathrm{OCH}_{2}\right), 124.49$ (C-3), 128.84 (C-6), 130.57 (C-4), 133.55 (C-5), 135.48 (C-1), 148.00 (C-2). Anal. Calcd for $\mathrm{C}_{11} \mathrm{H}_{15} \mathrm{NO}_{4} \mathrm{~S}_{2}$ (289.37): C, 45.66; H, 5.22; N, 4.84; S, 22.16. Found: C, 45.48; H, 5.24; N, 4.86; S, 22.24.

\section{Acknowledgements}

The authors greatly acknowledge the Russian Fund of Basic Researches (Grant No. 10-0300256a) for financial support of this work.

\section{References}

1. (a) Sugimura, T; Takayama, S. Environ Health Perspect. 1983, 47, 171. (b) Oda, Y.; Yamazaki, H.; Shimada, T. Carcinogenesis. 1999, 20, 1079. (c) Sabbioni, G. Chem. Res. Toxicol. 1994, 7, 267.

2. Granik, V. G.; Grigor'ev, N. B. Russ. Chem. Bull., Int. Ed. 2002, 51, 1973.

3. (a) Reutov, O. A.; Kurts, A. L.; Butin, K. P. Organic Chemistry. Vol. 2; BINOM: Moscow 2004. 623. (b) Donskaya, O. V.; Dolgushin, G. V.; Lopyrev, V. A. Chem. Heterocycl. Compd. 2002, 4, 435. (c) Porzelle, A.; Woodrow, M. D.; Tomkinson, N. C. O. Org. Lett. 2010, 12, 812. (d). Junge, K.; Wendt, B.; Shaikh, N.; Beller, M. Chem. Commun. 2010, 46, 1769. (e) Gulevskaya, A. V.; Verbeeck, S.; Burov, O. N.; Meyers, C.; Korbukova, I. N.; Herrebout, W.; Maes, B. U. W. Eur. J. Org. Chem. 2009, 4, 564. (f) Cho, C. S.; Kim, T. K.; Choi, H. J.; Kim, T. J.; Shim, S. C. Bull. Korean Chem. Soc. 2002, 23, 541. (g) Ono, N. The Nitro Group in Organic Synthesis; Wiley-VCH: New York. 2001, p 372. 
4. Macleod, C.; McKiernan, G. J.; Guthrie, E. J.; Farrugia, L. J.; Hamprecht, D. W.; Macritchie, J.; and Hartley, R. C. J. Org. Chem. 2003, 68, 387.

5. (a) Wang, Y.; Inguaggiato, G.; Jasamai, M.; Shah, M.; Hughes, D.; Sleater, M.; Simons, C. Bioorg. Med. Chem. 1999, 7, 481. (b) Martinez, A.; Esteban, A. I.; Herrero, A.; Ochoa, C.; Andrei, G.; Snoek, R.; Balzarini, J. Bioorg. Med. Chem. 1999, 7, 1617. (c) Camplo, M.; Charvet-Faury, A. S.; Borel, C.; Turin, F.; Hantz, O.; Trabaud, C.; Niddam, V.; Mourier, N.; Graciet, J. C.; Chermann, J. C.; Kraus J. L. European Journal of Med. Chem. 1996, 31, 539. (d) Belleau, B.; Brasili, L.; Chan, L.; DiMarco, M. P.; Zacharie, B.; Nguyen-Ba, N.; Jenkinson, H. J.; Coates, J. A. V.; Cameron, J. M. Bioorg. Med. Chem. Lett. 1993, 7, 1723. (e) Dion, Z. GB Pat. 2126405, 1991.

6. Ioannou, M.; Porter, M. J.; Saez. F. Chem. Commun. 2002, 346.

7. Karimi, B.; Seradj, H.; Maleki, J. Tetrahedron 2002, 58, 4513.

8. Krohn, K; Cludius-Brandt, S. Synthesis 2008, 15, 2369.

9. Mori, T.; Sawada, Y.; Oku, A. J. Org. Chem. 2000, 65, 3620.

10. Krohn, K; Cludius-Brandt, S. Synthesis 2010, 8, 1344.

11. Tang, S.; Han, J.; He, J.; Zheng, Jiyue.; He, Y.; Pan, X.; She, X. Tetrahedron Lett. 2008, 49, 1348.

12. Mikhailov, B. M., Ter-Sarkisyan, G. S. Izv. Acad. Nauk USSR. Otd. Khim. Nauk. 1960, 1888. Chem. Abstr. 1961, 55, 17562a.

13. Luh, T. Y. Acc. Chem. Res. 1991, 24, 257.

14. Ralls, J. W.; Dodson, R. M.; Riegel, B. J. Am. Chem. Soc. 1949, 71, 3320.

15. Djerassi, C.; Gorman. M. J. Am. Chem. Soc. 1953, 75, 3704.

16. Wilson, G. E.; Huang, M. G.; Schloman. W. W. J. Org. Chem. 1968, 33, 2133.

17. Kumar, V.; Dev, S. Tetrahedron Lett. 1983, 24, 1289.

18. Yadav, J. S.; Reddy, B. V. S.; Pandey. S. K Synth. Commun. 2002, 32, 715.

19. Fallis, A. G.; Yadav, V. K. Tetrahedron Lett. 1988, 29, 897.

20. (a) Karimi, B.; Ma'main L. Synthesis 2003, 2503. (b) Kazahaya, K.; Hamada, N.; Ito, S.; Sato, T. Synlett, 2002, 1535. (c) De, S.K. Tetrahedron Lett. 2004, 45, 2339. (d) Adibi, H.; Jafari, H. Journal of Fluorine Chem. 2007, 128, 679. (e) Rohman, Md. R.; Rajbangashi, M. B.; Laloo, M.; Sahu, P. R.; Myrboh. B. Tetrahedron Lett. 2010, 51, 2862.

21. Burczyk, B.; Kortylewicz, Z. Synthesis. 1982, 10, 831.

22. (a) Perni R.B. Synth. Commun. 1989, 19, 2383. (b) Chavan, S. P.; Soni, P.; Kamat, S. K. Synlett 2001, 1251. (c) Adibi, H.; Jafari, H. J. of Fluorine. Chem. 2007, 128, 679.

23. Papernaya, L. K.; Levanova, E. P.; Sykhomasova, E. N.; Albanov, A. I.; Deryagina, E. N. Russ. J. Org. Chem. (Engl. Transl.). 2003, 39, 1533.

24. Papernaya, L. K.; Levanova, E. P.; Sykhomasova, E. N.; Albanov, A. I.; Deryagina E. N. Russ. J. Org. Chem. (Engl. Transl.).2005, 41, 952.

25. Papernaya, L. K.; Levanova, E. P.; Sykhomasova, E. N.; Albanov, A. I.; Deryagina, E. N. Russ. J. Org. Chem. (Engl. Transl.). 2006, 42, 256.

26. Papernaya, L. K.; Levanova, E. P.; Sykhomasova, E. N.; Klyba L. V.; Zhanchipova, E. R.; Albanov, A. I.; Korchevin, N. A. Russ. J. Gen. Chem. (Engl.Transl.).2006, 76, 1123.

27. Volochnyuk, D. M.; Ryabukhin, S. V.; Plaskon, A. S.; Grigorenko, O. O. Synthesis 2009, $22,3719$. 
28. Turchaninova, L. P.; Korchevin, N. A.; Shipov, A. T.; Deriagina, E. N.; Baukov, Yu. I.; Voronkov, M. G. Zh. Obch. Khim. 1989, 59, 722; Chem. Abstr. 1989, 111, 194073e.

29. Azarifar, D.; Forghaniha, A. Jounal of the Chines Chem. Soc. 2006, 53, 1189.

30. Khan, Abu T.; Parvin, T.; Choudhury, L. H. Synthesis 2006, 15, 2497.

31. Kumar, A.; Rao, M. S.; Rao, V. K. Aust. J. Chem. 2010, 63, 135.

32. Kumar, A.; Jain, N.; Rana, S.; Chauhan, S. M. S. Synlett 2004, 15, 2785.

33. Kukovitskii, D. M.; Zorin, V. V.; Zelechonok Yu. B.; Zlotskii, S. S.; Rachmankulov, D. L.; Todres, Z. V. Russ. Zh. Org. Chem. 1983, 19, 145; Chem. Abstr. 1983, 98, 197487s.

34. Sebej, P.; Solomek, T.; Hroudna, L.; Brancova P.; Klan, P. J. Org. Chem. 2009, 74, 8647. 